\title{
Çukurova Üniversitesinde Okuyan Kadın ve Erkek Öğrencilerin Fiziksel Aktivite Düzeylerinin Incelenmesi
}

\author{
Cenab TÜRKER İ ${ }^{*}$, Barışcan ÖZTÜRK ${ }^{2}$, Bilgihan BÜYÜKTAŞ ${ }^{3}$
}

${ }^{1}$ Çukurova Üniversitesi Beden Eğitimi ve Spor Yüksekokulu, Adana, https://orcid.org/0000-0003-4850-9810

2Çukurova Üniversitesi Sağlık Bilimleri Enstitüsü, Adana, https://orcid.org/0000-0001-7001-3032

3Çukurova Üniversitesi Sağl1k Bilimleri Enstitüsü, Adana, https://orcid.org/0000-0002-6816-7275

Orijinal Makale

Gönderi Tarihi: 05.11.2019
Kabul Tarihi: 25.12.2019
DOI: $10.30769 /$ usbd.642774

Online Yayın Tarihi: 31.12.2019

\section{Öz}

Dünyadaki teknolojik gelişmeler insanların günlük hayatını her geçen gün daha kolaylaştırmakta ancak diğer yandan günlük hareket miktarını azaltmaktadır. Bunun sonucu hareketsizliğe bağlı hastalıklar artmakta, yaşam kalitesi ise düşmektedir. Bu çalışma Çukurova üniversitesinde okuyan öğrencilerin fiziksel aktivite düzeylerini belirlemek ve cinsiyetlere göre karşılaştırmak amacıyla yapılmıştır. Çalışmaya yaş ortalamaları $22,16 \pm 3,03$ yıl, boyları $1,72 \pm 0,09 \mathrm{~m}$ ve vücut ağırlık ortalamaları 67,22 $\pm 14,05 \mathrm{~kg}$ olan, kadın $136(\% 49,8)$ ve erkek $137(\% 50,2)$ toplam 273 üniversite öğrencisi katılmıştır. Katılımcıların BMI değerleri 22,54 $\pm 3,53 \mathrm{~kg} / \mathrm{m}^{2}$ normal aralıkta oldukları görülmüştür. Katılımcıların fiziksel aktivite düzeylerine bakıldığında kadın üniversite öğrencilerinin 20 (\%14,7) düşük düzeyde, $68(\% 50,0)$ orta düzeyde ve $48(\% 35,3)$ yüksek düzeyde fiziksel aktivite yaptığı, erkek üniversite öğrencilerinin ise $20(\% 14,6)$ düşük düzeyde, $49(\% 35,8)$ orta düzeyde ve $68(\% 49,6)$ yüksek düzeyde fiziksel aktivite yaptığı görülmüştür. Yürüme aktivitelerine bakıldığında kadın öğrencilerin $(595,23 \pm 690,21 \mathrm{dk} / \mathrm{hf})$ ile erkek öğrencilerden $(449,67 \pm 520,42 \mathrm{dk} / \mathrm{hf})$ daha iyi olduğu görülmüştür. Elde edilen sonuçlara göre öğrencilerin düşük şiddetli MET değerlerinde kadınlar lehine anlamlı farklılık bulunmuştur $(\mathrm{p} \leq 0,05)$. Orta ve şiddetli MET değerlerinde erkekler lehine anlamlı farklılık bulunmuştur. Çalışmaya katılan üniversite öğrencilerinin (\%78) BMI sınıflaması dikkate alındığında boy uzunluklarına göre vücut ağırlıklarının normal değerlerde olduğu görülmüştür. Ayrıca, fiziksel aktivite düzeylerinin yeterli seviyede olduğu, erkeklerin kadınlara göre daha yüksek fiziksel aktivite seviyesine sahip olduğu ve çalışmaya katılan üniversite öğrencilerinin günlük oturma sürelerinin diğer üniversite ögrencilerinden daha az olduğu bulunmuştur. Bunun sebebinin kampüs içerisindeki etkinlik alanlarının merkezde olmasından dolayı öğrencilerin gitmek istedikleri yere yürüyüş yaparak gitmeleri ve fiziksel aktivite düzeylerini olumlu olarak değiştirebilecek alanlara ve etkinliklere kolaylıkla ulaşabilmeleri olduğu söylenebilir.

Anahtar kelimeler: Fiziksel aktivite, Oturma süresi, BMI, Üniversite öğrencileri.

\section{Analyzing the Male and Female Students at Çukurova University on Physical Activity Levels}

\begin{abstract}
Technological developments in the world make people's daily lives easier every day, but on the other hand reduce the amount of daily movement. As a result, inactivity-related diseases increase and quality of life decreases. The aim of this study was to determine the physical activity levels of the students studying at Cukurova University and to compare them according to gender. A total of 273 university students, female $136(49.8 \%)$ and male $137(50.2 \%)$, who had an average age of $22.16 \pm 3.03$ years, height of $1.72 \pm 0.09 \mathrm{~m}$ and body weight averages of $67.22 \pm 14.05 \mathrm{~kg}$, participated in the study. BMI values of the participants were found to be within the normal range of $22.54 \pm 3.53 \mathrm{~kg} / \mathrm{m}^{2}$. When the physical activity levels of the participants were examined, it was seen that $20(14.7 \%)$ low level, $68(50.0 \%)$ moderate and $48(35.3 \%)$ high level of physical activity were performed by female university students. Male university students had 20 (14.6\%) low, 49 (35.8\%) moderate and $68(49.6 \%)$ high levels of physical activity. When walking activities were examined, it was found that female students $(595,23 \pm 690,21 \mathrm{~min} / \mathrm{week})$ and male students $(449,67 \pm 520,42 \mathrm{~min} /$ week $)$ were better. According to the results, a significant difference was found in favor of women in low-intensity MET values of students $(\mathrm{p} \leq 0,05)$. Moderate and high MET values were found to differ significantly in favor of males. When BMI classification of the university students (78\%) was taken into consideration, body weights were found to be normal according to their height. In addition, it was found that physical activity levels were sufficient, males had higher physical activity levels than females, and the daily sitting time of the university students participating in the study was found to be less than that of other university students. The reason for this can be said that because the activity areas on campus are in the center, students can walk to where they want to go and easily access the areas and activities that can positively change their physical activity levels.
\end{abstract}

Keywords: Physical activity, Sitting time, BMI, University students.

\footnotetext{
* Sorumlu Yazar: Cenab TÜRKERİ, cturkeri@cu.edu.tr
} 


\section{GíRiş}

Dünyadaki teknolojik gelişmeler insanların günlük hayatını her geçen gün daha kolaylaştırmakta ancak diğer bir yandan günlük hareket miktarını azaltmaktadır. Bunun sonucu hareketsizliğe bağlı hastalıklar artmakta, yaşam kalitesi ise düşmektedir. Kas iskelet sistemlerinde zayıflama ve işlev bozuklukları, dolaşım ve solunum sistemlerinde çok önemli problemler ortaya çıkmaktadır. Ayrıca bunlara bağlı olarak iş gücünde azalma ve genel ekonomik kayıplar da oluşmaktadır. Dünya Sağlık Örgütü’nün 2002 yılı raporuna göre hareketsiz yaşam dünya çapında yılda ortalama 1,9 milyon kişinin ölümüne neden olmaktadır. Günümüzde sağlıklı yaşlanmak, yaşam kalitesini arttırmak ve yaşa bağlı sağlık risklerini en aza indirebilmek için gerekli olan temel iki etmen sağlıklı beslenme ve fiziksel aktivitedir (WHO, 2002 Report).

Düzenli olarak yapılan fiziksel aktivite ve spor insanlarda meydana gelen veya gelebilecek fazla kiloluk ve obeziteyi engelleme konusunda alınabilecek en önemli önlemlerden birisi olduğu görülmektedir (Uluöz ve ark., 2017). Fiziksel aktivitenin artması gündelik hayattaki faaliyetleri kolaylaştırmakla birlikte bireylerin iş ve yaşam performanslarına da olumlu katkı sağlayacaktır. Çocukluktan yaşlılığa hemen her dönemde sağlıklı beslenme ve fiziksel aktivite önemlidir. Ancak erken yaşlarda kazanılan egzersiz ve fiziksel aktivite alışkanlıkları sürdürülebilirse giderek yaşam tarzına dönüşebilmekte ve hareketsizliğe bağlı gelişebilecek riskleri yok etmektedir. Tüm bunlardan dolayı, doğru önerilerin yapılabilmesi ve önlemler alınabilmesi için özellikle gençlerin fiziksel aktivite durumlarını araştırmak, incelemek önem kazanmaktadır. YÖK'ün 2018-2019 yılı istatistiklerine göre 7.740 .502 kişi üniversitelerde okumaktadır. Bu sayı ülkemizde genç nüfusun önemli bir miktarını oluşturmaktadır.

Fiziksel aktivite düzeyi ile ilgili araştırmalar için üzerinde çalışılacak grubu seçmek önemli bir husustur. Von ve Fridlund (2005) "Öğrenciler nispeten sağlıklı, homojen ve ulaşılabilir bir grubu kapsar. Ayrıca, genç yetişkinlerin fiziksel aktivite düzeyi, ileri yaşlarda sorun yaratabilecek önlenebilir hastalıkların görülme sıklığını etkilemektedir. $\mathrm{Bu}$ nedenle, değerlendirme çalışmalarının bu grupta başlatılması uygun bulunmaktadır” demektedir. Benzer düşünceyle araştırmamızda çalışma grubu olarak üniversite öğrencileri hedeflenmiştir. Ülkemizde Üniversite öğrencilerinde fiziksel aktiviteyi araştıran çalışmalar vardır (Savcı ve ark, 2006; Soyuer, Ünalan ve Elmalı, 2010; Çalıştır, Dereli ve Eksen, 2005). $\mathrm{Bu}$ bağlamda çalışmada amacımız; üniversitede okumakta olan öğrencilerin fiziksel aktivite düzeylerinin belirlenmesi ve buna ek olarak cinsiyetlerine göre öğrencilerin fiziksel aktivite düzeylerini karşılaştırarak literatüre katkı sağlanmasıdır.

\section{GEREÇ VE YÖNTEM}

\section{Araştırma Modeli}

$\mathrm{Bu}$ araştırmada tarama modeli kullanılmıştır.

\section{Katılımcilar}

Araştırmanın evreni 2018-2019 eğitim öğretim yılında, Çukurova Üniversitesi’nde okuyan öğrencilerdir. Örneklemi ise öğretimine devam eden öğrenciler arasından basit tesadüfi yöntemle seçilmiş ve gönüllü olarak katılmayı kabul eden 136 kadın $(\% 49,8)$ ve 137 erkek 
(\% 50,2) toplam 273 üniversite öğrencisinden oluşmaktadır. Katılımcılara çalışmaya başlamadan önce gerekli açıklamalar yapılmış ve gönüllülük formları imzalatılmıştır.

\section{Veri Toplama Araci}

Demografik Özellikler: Çalışmaya katılan bireylerin demografik özelliklerinin (cinsiyet, yaş, boy, ağırlık vb) belirlenmesi amacıyla araştırmacılar tarafından oluşturulan anket formu kullanılmıştır.

Uluslararası Fiziksel Aktivite Anketi (IPAQ): Öğrencilere fiziksel aktivite düzeylerini belirlemek amacıyla Uluslararası Fiziksel Aktivite Anketi (IPAQ) uygulatılmıştır. Anket, uluslararası arenada günlük olarak yapılan fiziksel aktivitenin bireysel raporlara dayanarak düzeyi hakkında geçerli ve karşılaştırılabilir bilgi elde etmek amacıyla geliştirilmiştir. Ölçeğin Türkiye'de geçerlik ve güvenirlik çalışması 2005 yılında Öztürk tarafından yapılmıştır (Öztürk, 2005).

Anket, son 7 günde en az $10 \mathrm{dk}$ yapılan Fiziksel aktivite ile ilgili sorular içermektedir. Ankette son haftada kaç gün ve her bir gün için ne kadar süre ile şiddetli fiziksel aktiviteler (ŞFA), orta dereceli fiziksel aktiviteler (OFA) ve yürüme (Y) yapıldığı belirlenmektedir. Son soruda ise günlük olarak hareket etmeden (oturarak, yatarak vs) harcanan zaman belirlenmektedir (Bozkuş ve ark., 2013).

Uluslararası Fiziksel Aktivite Anketi (IPAQ) Testi Uygulama Protokolü: Fiziksel aktivite düzeyini belirlemek için MET yöntemiyle yapılmaktadır. MET=3,5 $\mathrm{ml} / \mathrm{kg} / \mathrm{dk}$. İstirahat halinde iken her kişi, bir $\mathrm{kg}$ başına bir dakikada 3,5 $\mathrm{ml}$ oksijen tüketmektedir. IPAQ'ta, (ŞFA=8,0 MET), (OFA=4,0 MET) ve (Y=3,3 MET) olarak harcandığı kabul edilmektedir. Kişinin haftada kaç gün ve ne kadar süre ile ŞFA, OFA ve Y yaptığını tespit ederek bu üç farklı fiziksel aktivitede harcanan toplam MET miktarı hesaplanmaktadır. Örnek Tablo 1'de verilmektedir (Bozkuş ve ark., 2013).

Tablo 1. MET yöntemiyle FA düzeylerinin belirlenmesi (Örnek hesaplama)

\begin{tabular}{ccccc}
\hline Fiziksel Aktivite Tipi & MET & Günde/dk & Hafta/gün & Toplam \\
\hline Y & 3.3 & 30 & 5 & 495 MET \\
\hline OFA & 4 & 40 & 4 & 640 MET \\
\hline SSFA & 8 & 30 & 3 & 720 MET \\
\hline Toplam & & & & 1855 MET min/hafta \\
\hline
\end{tabular}

Toplam fiziksel aktivite skoruna göre katılımcıların fiziksel aktivite düzeyleri "düşük, orta ve yüksek" biçiminde sınıflandırılmıştır (Clarig ve ark.,2003).

1. Düşük düzey: $600 \mathrm{MET}-\mathrm{dk} / \mathrm{hafta}$ altı.

2. Orta düzey: 600-3000 MET-dk/hafta aras1.

3. Yüksek düzey: $3000 \mathrm{MET}-\mathrm{dk} / \mathrm{hafta}$ üstü.

\section{BMI (Body Mass Index)}

Body Mass Index (BMI) vücut ağırlı̆̆ının boyun karesine bölünmesi $\left(\mathrm{kg} / \mathrm{m}^{2}\right)$ ile bulunur. Vücut kitle indeksi değerlendirmesi sağlık bakanlığı tarafindan yayınlanan Tablo2'de verilen değerlendirme tablosuna göre yapılır. 
Tablo 2. BMI değerlendirme tablosu

\begin{tabular}{lll}
\hline 18,5 & $\mathrm{~kg} / \mathrm{m}^{2}$ altında olanlar & Zayıf \\
$18,5-24,9$ & $\mathrm{~kg} / \mathrm{m}^{2}$ altında olanlar & Normal Kilolu \\
$25-29,9$ & $\mathrm{~kg} / \mathrm{m}^{2}$ altında olanlar & Fazla Kilolu \\
$30-39,9$ & $\mathrm{~kg} / \mathrm{m}^{2}$ altında olanlar & Obez \\
\hline
\end{tabular}

\section{İstatistiksel Analiz}

İstatistiksel analizlerde, SPSS 22,0 paket programı kullanılmıştır. Verilerin normal dağılımları için Kolmogorov- Smirnov testi sonuçlarına bakılmıştır. Veriler normal dağılım göstermediği için karşılaştırmalarda non-parametrik testlerden Mann-Whitney $U$ testi kullanılmıştır. Sonuçlar (ortalama \pm standart sapma) olarak verildi. Anlamlılık düzeyi $p \leq 0,05$ olarak kabul edilmiştir.

\section{BULGULAR}

Çalışmaya katılan kadın $136(\% 49,8)$ ve erkek $137(\% 50,2)$ toplam 273 üniversite öğrencisinin demografik verileri incelendiğinde, yaş ortalamalarının 22,16 $\pm 3,03$ yıl, boylarının 1,72 $\pm 0,09 \mathrm{~m}$ olduğu, vücut ağırlıklarının $67,22 \pm 14,05 \mathrm{~kg}$ olduğu görülmüştür. BMI değerleri ortalamalarına bakıldığında, katılımcıların $22,54 \pm 3,53 \mathrm{~kg} / \mathrm{m}^{2}$ normal aralıkta oldukları görülmüştür.

Tablo 3. Kadın ve erkek üniversite öğrencilerinin demografik özellikleri

\begin{tabular}{lccc}
\hline & Kadın & Erkek & Toplam \\
& $\square \pm$ SS & $\square \pm$ SS & $\square \pm$ SS \\
\hline Yaş (yıl) & $21,57 \pm 3,31$ & $22,71 \pm 2,53$ & $22,16 \pm 3,03$ \\
Boy (m) & $1,66 \pm 0,06$ & $1,73 \pm 2,60$ & $1,72 \pm 0,88$ \\
Vücut Ă̆ırlığı (kg) & $57,88 \pm 10,61$ & $76,50 \pm 10,46$ & $67,22 \pm 14,05$ \\
BMI & $21,08 \pm 3,56$ & $23,99 \pm 2,85$ & $22,54 \pm 3,53$ \\
\hline
\end{tabular}

Tablo 4'te kadın ve erkek öğrencilerin BMI değerlerine bakıldığında kadın öğrencilerin 24 $(\% 17,6)$ zayıf, $100(\% 73,5)$ normal, $10(\% 7,4)$ fazla kilolu ve $2(\% 1,5)$ obez değerlerinde olduğu görülmektedir. Erkek öğrencilerin ise $3(\% 2,2)$ zayıf, $86(\% 62,8)$ normal, $45(\% 32,8)$ fazla kilolu ve $3(\% 2,2)$ obez sınıflamasında olduğu görülmüştür.

Tablo 4. Kadın ve erkek üniversite öğrencilerinin BMI değerleri sınıflandırması

\begin{tabular}{lcccccc}
\hline & \multicolumn{2}{c}{ Kadın } & \multicolumn{3}{c}{ Erkek } & \multicolumn{2}{c}{ Toplam } \\
\hline Zayıf & 24 & 17,6 & 3 & 2,2 & 27 & 9,9 \\
Normal Kilolu & 100 & 73,5 & 86 & 62,8 & 186 & 68,1 \\
Fazla Kilolu & 10 & 7,4 & 45 & 32,8 & 55 & 20,2 \\
Obez & 2 & 1,5 & 3 & 2,2 & 5 & 1,8 \\
\hline Toplam & 136 & 100,0 & 137 & 100,0 & 273 & 100,0
\end{tabular}

Tablo 5'te kadın ve erkek üniversite öğrencilerinin fiziksel aktivite düzeyi dağılımlarına bakıldığında kadın üniversite öğrencilerinin $20(\% 14,7)$ düşük düzeyde, $68(\% 50,0)$ orta düzeyde ve $48(\% 35,3)$ yüksek düzeyde fiziksel aktivite yaptığı görülmüştür. Erkek üniversite öğrencilerinin ise $20(\% 14,6)$ düşük düzeyde, $49(\% 35,8)$ orta düzeyde ve 68 $(\% 49,6)$ yüksek düzeyde fiziksel aktivite yaptığı görülmüsstür. 
Tablo 5. Kadın ve erkek üniversite öğrencilerin fiziksel aktivite düzeyi dağılımı

\begin{tabular}{lcccccc}
\hline & \multicolumn{2}{c}{ Kadın } & \multicolumn{2}{c}{ Erkek } & \multicolumn{2}{c}{ Toplam } \\
\hline Düşük & $\mathbf{N}$ & $\mathbf{\%}$ & $\mathbf{N}$ & $\mathbf{\%}$ & $\mathbf{\%}$ \\
Orta & 20 & 14,7 & 20 & 14,6 & 40 & 14,7 \\
Yüksek & 68 & 50,0 & 49 & 35,8 & 117 & 42,8 \\
Toplam & 48 & 35,3 & 68 & 49,6 & 116 & 42,5 \\
\hline
\end{tabular}

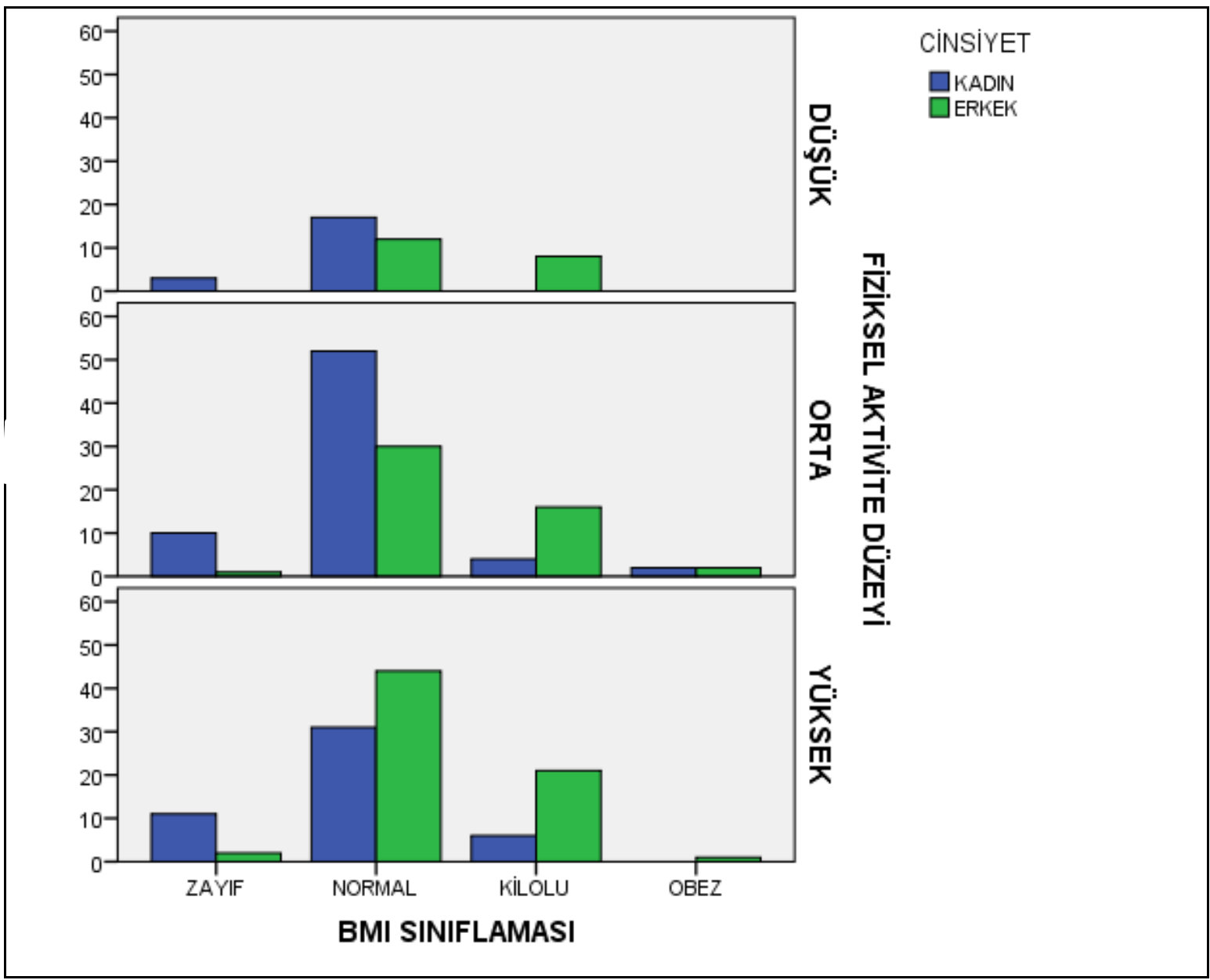

Şekil 1. Katılımcıların cinsiyete göre BMI sınıflaması ve fiziksel aktivite düzeyleri

Tablo 6'da kadın ve erkek üniversite öğrencilerinin haftalık şiddetli fiziksel aktivite, orta dereceli fiziksel aktivite ve yürüme süreleri ile günlük oturma süreleri verilmiştir. Buna göre kadın öğrencilerin günlük yürüme aktivitesinin $(595,23 \pm 690,21 \mathrm{dk} / \mathrm{hf})$ ile erkek öğrencilerden $(449,67 \pm 520,42 \mathrm{dk} / \mathrm{hf})$ daha iyi olduğu görülmüştür.

Tablo 6. Kadın erkek fiziksel aktivite ve günlük oturma süreleri

\begin{tabular}{lccc}
\hline & $\begin{array}{c}\text { Kadın } \\
\text { N=136 }\end{array}$ & $\begin{array}{c}\text { Erkek } \\
\mathbf{N = 1 3 7}\end{array}$ & $\begin{array}{c}\text { Toplam } \\
\text { N=273 }\end{array}$ \\
\hline Şiddetli Fiziksel Aktivite (dk/hf) & $113,64 \pm 265,38$ & $180,98 \pm 222,92$ & $147,43 \pm 246,86$ \\
Orta Dereceli Fiziksel Aktivite (dk/hf) & $99,67 \pm 221,46$ & $161,16 \pm 335,39$ & $130,52 \pm 285,56$ \\
Yürüme (dk/hf) & $595,23 \pm 690,21$ & $449,67 \pm 520,42$ & $522,18 \pm 614,15$ \\
Toplam Fiziksel Aktivite (MET-dk/hf) & $3221,60 \pm 3851,90$ & $3816,30 \pm 4084,42$ & $3520,04 \pm 3974,17$ \\
Oturma (dk/gün) & $273,16 \pm 153,44$ & $284,34 \pm 162,02$ & $278,77 \pm 157,61$ \\
\hline
\end{tabular}


Tablo 7'de haftalık MET değerleri Mann-Whitney U testi sonuçları verilmiştir. Elde edilen sonuçlara göre kadın üniversite öğrencilerinin erkek üniversite öğrencilerine göre düşük şiddetli MET değerleri arasında kadınlar lehine anlamlı farklılık bulunmuştur $(\mathrm{p} \leq 0,05)$. Erkek üniversite öğrencilerinin ise orta ve şiddetli MET değerleri arasında erkekler lehine anlamlı farklılık bulunmuştur $(\mathrm{p} \leq 0,00)$.

Tablo 7. Kadın ve erkek üniversite öğrencilerinin haftalık met değerlerinin mann-whitney u testi sonuçları

\begin{tabular}{lccccccc}
\hline & Grup & $\mathrm{N}$ & $\begin{array}{c}\text { Sira } \\
\text { Ortalamas }\end{array}$ & $\begin{array}{c}\text { Sira } \\
\text { Toplamı }\end{array}$ & $\mathrm{U}$ & $\mathrm{Z}$ & $\mathrm{p}$ \\
\hline \multirow{2}{*}{ Şiddetli } & Kadın & 136 & 118,78 & 16154,50 & \multirow{2}{*}{6838,50} & $-4,064$ & $0,00^{*}$ \\
& Erkek & 137 & 155,08 & 21246,50 & & & \\
\multirow{2}{*}{ Orta } & Kadın & 136 & 123,93 & 16854,50 & & & \\
\multirow{3}{*}{ Düşük } & Erkek & 137 & 149,97 & 20546,50 & 7538,50 & $-2,917$ & $0,00^{*}$ \\
& Kadın & 136 & 146,15 & 19876,50 & & & \\
& Erkek & 137 & 127,92 & 17524,50 & 8071,50 & $-1,913$ & $0,05^{*}$ \\
\hline
\end{tabular}

$* \mathbf{p} \leq \mathbf{0 , 0 5}$

\section{TARTIŞMA}

Genel olarak medya unsurları ve özelde bilimsel araştırmalar giderek artan sayıda insanın obez sınıflamasına girdiğini söylemektedir. Obezite ve morbit obezite durumu halk sağlı̆̆ını en fazla etkileyen ve ölüm sebepleri açısından ilk sıralarda yer alan özellikle hareketsizlik ve yanlış beslenmeyle gelişen toplumsal bir sorundur. Daha fazla insanın düzenli spor yapmaya teşvik edilmesi çok yerinde bir öneri olmasına rağmen bunu yapamayanların fiziksel aktivitelerini artırmaları konusunda bilgilendirilmesi gerekmektedir. Fiziksel aktivitenin sağlığa yararları birçok makalede vurgulanmaktadır. Her düzeyde fiziksel aktivitenin yaşam kalitesini artırıcı etkisi olacağı açıktır. Ancak Fiziksel aktivitenin sağlık açısından yarar sağlayabilmesi için, haftanın her gününde veya çoğu gününde, 30 dakika veya üzerinde orta düzeyde şiddette yapılması gerekmektedir (Savc1 ve ark., 2006; Driskell, Kim ve Goebel, 2005). Scott ve ark. 2000 yılında fiziksel aktivite kurallarına uyma ile ilgili yapmış oldukları çalışma bulgularına göre; fiziksel aktivite, fiziksel etkinliği önemli olarak algılayanlar arasında daha yaygındır. Çalışmamız üniversite öğrencilerinin fiziksel aktivite düzeylerinin belirlenmesi ve sonuçların cinsiyete göre karşılaştırılması amacıyla yapılmıştır.

Çalışmamızda üniversite öğrencilerinin BMI değerleri incelendiğinde \%9,9'u zayıf ve \%68,1'i normal kilolu, \%20,2'si fazla kilolu ve \%1,8'inin ise obez siniflamasına dahil olduğu görülmüştür. Üniversite öğrencileri üzerine yapılan birçok çalışmada öğrencilerin genelde normal ağırlık sınırlarında olduğu bulunmuştur (Saygın ve ark., 2011; Öztürk, 2005; Genç ve ark., 2011; Aslan, Livanelioğlu, Aslan, 2007). Bu durum çalışmamızda elde ettiğimiz değerler ile örtüşmektedir.

Çalışmamızda elde ettiğimiz fiziksel aktivite düzeyi verilerine göre üniversite öğrencilerinin $\% 14,7$ 'si düşük düzeyde, 42,8 'i orta düzeyde ve $\% 42,5$ 'inin yüksek düzeyde fiziksel aktivite yaptığı görülmüştür. Bu sonuçlar birçok çalışmayla birlikte Ölçücü ve ark. (2015) ile Savc1 ve ark.'nın (2006) bulgularıyla yaklaşık değerlerdedir. BMI değerleri de göz önüne alındığında öğrencilerin çoğunluğunun orta ve yüksek şiddette fiziksel aktivite yaptığ $(\% 85,3)$ ve düşük ve normal ağırlık değerlerinde olduğu $(\% 78,0)$ görülmektedir. Faydaoğlu, 
Energin ve Sürücüoğlu 2013 yılında Ankara üniversitesi öğrencileri üzerinde yapmış oldukları çalışmada kızların \%84,2'sinin erkeklerin ise \%71,4'ünün normal ağırlıkta olduğunu ve erkeklerde zayıflığa rastlanmazken kızların \%10'unun zayıf olduğu belirlenmiştir. Bu durumda çalışmamızda katılımcı öğrencilerin hem fiziksel olarak aktif hem de beden kompozisyonlarının iyi olduğu düşünülebilir.

Kadın ve erkek üniversite öğrencilerinin fiziksel aktivite düzeyleri incelendiğinde, kadın üniversite öğrencilerinin $\% 14,7$ düşük düzeyde, $\% 50,0$ orta düzeyde ve $\% 35,3$ yüksek düzeyde fiziksel aktivite yaptığı, erkek üniversite öğrencilerinin ise $\% 14,6$ düşük düzeyde, $\% 35,8$ orta düzeyde ve \%49,6'sının yüksek düzeyde fiziksel aktivite yaptığı bulunmuştur. Toplam fiziksel aktivite düzeylerine bakıldığında düşük ve orta fiziksel aktivitenin \% 57,5 olduğu görülmektedir. Martin ve ark. (2000) üniversite öğrencilerinin \% 51'nin fiziksel aktivite düzeylerinin düşük olduğunu bulmuştur. Üniversite öğrencileri üzerinde farklı zaman ve yerlerde yapılan çalışmalarda fiziksel aktivite düzeyi düşük bulunmuştur (Savc1, 2006; Soyuer, Ünalan ve Elmal1, 2010; Alricsson, ve ark. 20 06; Öztürk, 2005; Ölçücü, 2015; Aslan, Livanelioğlu ve Aslan, 2007). Çalışmamızda tespit edilen orta ve yüksek düzeyde fiziksel aktivite düzeyinin literatürde belirtilen değerlerden bir miktar daha fazla çıkmış olmasının sebebi; Çukurova üniversitesi kampüsü içerisindeki rekreasyon alanları, spor sahaları ve öğrencilerin aktif katılım sergilediği kulüp ve toplulukların çalışma yerlerinin tamamının fakülteler ve dersliklerin tam merkezinde olması ve öğrencilerin sıklıkla bu faaliyetlerden yararlanmaları olabilir. Ancak daha doğru bir tespit yapılabilmesi için daha kapsamlı bir araştırma deseni oluşturulması gerekmektedir.

Kadın ve erkek üniversite öğrencilerinin günlük oturma süreleri incelendiğinde, kadın üniversite öğrencilerinin $273,16 \pm 153,44 \mathrm{dk}$, erkek üniversite öğrencilerinin 284,34 $\pm 162,02$ dk ve üniversite öğrencilerinin günlük toplam oturma süreleri ortalaması ise $278,77 \pm 157,61$ dk olarak bulunmuştur. Savcı ve ark. (2006) üniversite öğrencilerinin fiziksel aktivite düzeylerini karşılaştırdıkları bir çalışmada öğrencilerin günlük oturma sürelerini $470 \pm 185 \mathrm{dk}$ olarak bulmuştur. Üçok ve ark. (2011) Tıp fakültesindeki üniversite öğrencilerinin fiziksel aktivite düzeylerini belirlemek amacıyla yaptığ 1 bir çalışmada, tıp fakültesi öğrencilerinin günlük oturma sürelerini 320,6 $\pm 179,2 \mathrm{dk}$ olarak bulmuştur. İpek (2018) genç yetişkinlerin fiziksel aktivite düzeylerini karşılaştırdığı çalışmada ise kadınların günlük oturma sürelerini 433,5 $\pm 248,6 \mathrm{dk}$ ve erkeklerin 365,1 $\pm 246,7 \mathrm{dk}$ olarak bulmuştur. Genç ve ark. (2011) tarafından yapılan genç yetişkinlerin fiziksel aktivite düzeylerini karşılaştırıdıkları bir başka çalışmada ise genç kadınların günlük oturma süreleri 440,6 $\pm 184,8 \mathrm{dk}$ ve genç erkeklerin günlük oturma süreleri $428,7 \pm 185,0 \mathrm{dk}$ olarak bulunmuştur. Günlük oturma süreleri bakımından yapılan çalışmalar incelendiğinde, çalışmamızda elde ettiğimiz günlük oturma sürelerinin daha düşük olduğu görülmektedir. Bunun sebebi, çalışmaya katılan üniversite öğrencilerinin kampüs içindeki gündelik yaşamlarında dersler, etütler dışında çok kolayca ulaşabildikleri sportif, sosyal etkinlik alanları ve rekreasyon faaliyetlerine yoğun katılımdan kaynaklandığı düşünülebilir.

Üniversite öğrencilerinin haftalık fiziksel aktivite süreleri incelendiğinde, kadın öğrencilerin haftalık şiddetli fiziksel aktivite $113,64 \pm 265,38 \mathrm{dk}$, orta dereceli fiziksel aktivite $99,67 \pm 221,46 \mathrm{dk}$, yürüme süreleri 595,23 $\pm 690,21 \mathrm{dk}$, toplam fiziksel aktivite MET değerleri 


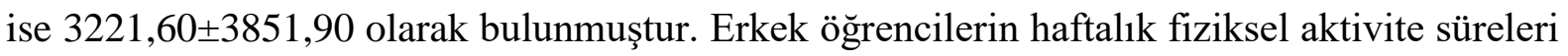
incelendiğinde, şiddetli fiziksel aktivite $180,98 \pm 222,92 \mathrm{dk}$, orta dereceli fiziksel aktivite

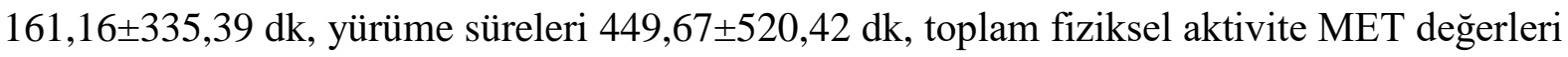

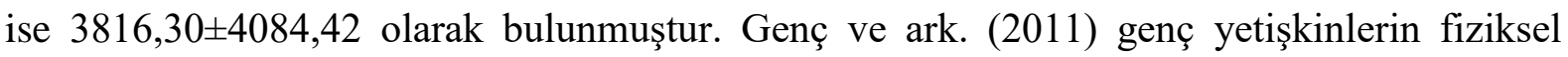
aktivite düzeylerini karşılaştırıdıkları bir çalışmada genç kadınların şiddetli fiziksel aktivite sürelerini $29,7 \pm 89,5 \mathrm{dk}$, orta dereceli fiziksel aktivite sürelerini $91,2 \pm 172,3 \mathrm{dk}$, yürüme sürelerini 459,6 $\pm 393,0 \mathrm{dk}$ ve toplam MET değerlerini 2099,2 $\pm 1727,2$ olarak bulmuştur. Erkek genç yetişkinlerin şiddetli fiziksel aktivite sürelerini $96,6 \pm 156,1 \mathrm{dk}$, orta dereceli fiziksel aktivite sürelerini $153.9 \pm 267,5 \mathrm{dk}$, yürüme sürelerini $502,1 \pm 434,9 \mathrm{dk}$ ve toplam fiziksel aktivite MET değerini ise 3010,7 $\pm 2246,9$ olarak bulmuştur. Haftalık fiziksel aktivite süresi ve fiziksel aktivite düzeyleri doğrudan ilişkili parametrelerdir. Çalışmamızda erkek üniversite öğrencilerinin fiziksel aktivite süreleri ve fiziksel aktivite düzeyleri kadın üniversite öğrencilerinden daha yüksek olduğu bulunmuştur. Literatür incelendiğinde yapılan birçok çalışmada erkek üniversite öğrencilerinin fiziksel aktivite düzeyleri kadın üniversite öğrencilerinden daha yüksek bulunmuştur (Arslan, Daşkapan ve Çakır, 2016; Guthold ve ark, 2008; Burton ve Turrell, 2000). Yapılan çalışmalarda elde edilen sonuçlar ile çalışmamızda elde edilen sonuçlar birbiriyle örtüşmektedir.

\section{SONUÇ}

Sonuç olarak, çalışmaya katılan üniversite öğrencilerinin büyük çoğunluğunun zayıf ve normal ağırlık aralığında olduğu ve boy uzunluklarına göre vücut ağırlıklarının normal değerlerde olduğu görülmüştür. Ayrıca, fiziksel aktivite düzeylerinin yeterli seviyede olduğu, erkeklerin kadınlara göre daha yüksek fiziksel aktivite seviyesine sahip olduğu ve çalışmaya katılan üniversite öğrencilerinin günlük oturma sürelerinin diğer üniversite öğrencilerinden daha az olduğu bulunmuştur. Bunun sebebinin; çalışmanın yapıldı̆̆ Çukurova üniversitesinin neredeyse tüm fakülteleri, yüksekokulları, merkezi kütüphanesi, kafeteryaları ve enstitüleri sportif, sosyal ve kültürel etkinlik alanlarının yakın çevresinde yer alması olduğu düşünülebilir. Ayrıca kampüs içerisindeki etkinlik alanlarının merkezde olmasından dolayı öğrenciler sıklıkla bir yerden diğer bir yere yürüyüş yaparak gitmekte ve fiziksel aktivite düzeylerini olumlu olarak değiştirebilecek alanlara ve etkinliklere kolaylıkla ulaşabilmekte bundan kaynaklı olarak da daha yüksek fiziksel aktivite düzeylerine ve normal boy ağırlık oranlarına sahip oldukları söylenebilir.

\section{ÖNERILER}

1- Bu çalışma daha yüksek sayıda üniversite öğrencisine ulaşılarak yapılmalı.

2- Fiziksel aktivitelerin kampüs alanı içerisinde gerçekleşme durumu incelenmeli.

3- Öğrencilerin beslenme alışkanlıkları ve yeterliği de araştırılmalı.

4- Örneklem deseni tüm fakülteleri ayrıca temsil edecek şekilde seçilmelidir. 


\section{KAYNAKLAR}

Ainsworth, B.E., Haskell, W.L., Leon, A.S., et al. (1993). Compendium of physical activities: classification of energy cost of human physical activities. Med Sci Sports Exerc., 25:71-80.

Alricsson, M., Landstad, B.J., Romild, U., et al. (2006). Self-related health, physical activity and complaints in Swedish high school students. Scientific World Journal. 6,816- 826.

Arslan, S. A., Daşkapan, A., Çakır, B. (2016). Üniversite öğrencilerinin beslenme ve fiziksel aktivite alışkanlıklarının belirlenmesi. TAF Preventive Medicine Bulletin, 15(3), 171-180.

Aslan, B. U., Livanelioğlu A., Aslan Ş. (2007). Fiziksel aktivite düzeyinin üniversite öğrencilerinde iki farklı yöntemle değerlendirilmesi. Fizyoterapi Rehabilitasyon, 18(1), 11-19.

Bozkuş, T., Türkmen, M., Kul, M., Özkan, A., Öz Ü., Cengiz, C. (2013). Beden eğitimi ve spor yüksekokulu'nda öğrenim gören öğrencilerin fiziksel aktivite düzeyleri ile sağlikli yaşam biçimi davranışlarının belirlenmesi ve ilişkilendirilmesi. International Journal of Sport Culture and Science, 1(3), 49-65.

Burke, S.M., Carron, A.V., Eys, M.A. (2005). Physical activity context and university student's propensity to meet the guidelines Centers for Disease Control and Prevention/American College of Sports Medicine. Med Sci Monit.11:CR171-176.

Burton, N.W., Turrell, G. (2000). Occupation, hours worked, and leisure-time physical activity. Prev Med., 31:673-81.

Craig, C. L., Marshall, A. L., Sjöström, M., Bauman, A. E., Booth, M. L., Ainsworth, B. E., ... \& Oja, P. (2003). International physical activity questionnaire: 12-country reliability and validity. Medicine \& science in sports \& exercise, 35(8), 1381-1395.

Çalıştır, B., Dereli, F., Eksen, M. (2005). Muğla üniversitesi öğrencilerinin beslenme konusunda bilgi düzeylerinin belirlenmesi. Journal of Human Sciences, 2(2), 1-8.

Driskell, J.A., Kim, Y.N., Goebel, K.J. (2005). Few differences found in the typical eating and physical activity habits of lower-level and upper-level university students. Journal of American Dietetic Association; 105:798-801.

Faydaoğlu, E., Energin, E., Sürücüoğlu, MS. (2013). Ankara Üniversitesi Sağl1k Bilimleri Fakültesinde okuyan öğrencilerin kahvaltı yapma alışkanlıklarının saptanması. Gümüşhane Üniversitesi Să̆llk Bilimleri Dergisi, 2(3), 299- 311.

Genç, A., Şener, Ü., Karabacak, H., Üçok, K. (2011). Kadın ve erkek genç erişkinler arasında fiziksel aktivite ve yaşam kalitesi farklılıklarının araştırılması. Kocatepe Tıp Dergisi The Medical Journal of Kocatepe 12: $145-150$

Guthold, R., Ono, T., Strong, K.I., Chatteerji, S., Morabia, A.M. (2008). Worldwide variability in physical inactivity: a 51- country survey. Am J Prev Med., 34(6):486-494.

Haase, A., Steptoe, A., Sallis, J.F., et al. (2004). Leisure-time physical activity in university students from 23 countries: associations with health beliefs, risk awareness, and national economic development. Prev Med., 39:182-190.

https://istatistik.yok.gov.tr/ Erişim Tarihi: 03.09.2019

İpek, C. (2018). Genç yetişkinlerde fiziksel aktivite düzeyi ve vücut kompozisyonu arasındaki ilişkinin incelenmesi. Yüksek Lisans Tezi. Selçuk Üniversitesi Sağlık Bilimleri Enstitüsü.

Karaca, A., Ergen, E., Koruç, Z. (2000). Fiziksel aktivite değerlendirme anketi (FADA) güvenilirlik ve geçerlilik çalışması. Spor Bilimleri Dergisi, 11:17-28. 
Karaca, A. (2000). Fiziksel aktivite değerlendirme anketinin (FADA) üniversite öğrencileri üzerinde güvenilirlik çalışması. 6. Spor Bilimleri Kongresi Bildiri Kitabı. Ankara.

La Porte, R.E., Monteye, H.J., Caspersen, C.J. (1985). Assessment of physical activity in epidemiologic research problems and prospects. Public Health Rep., 100,131-146.

Martin, S.B., Morrow, J.R., Jackson, A.W., Dunn, A.L. (2000). Variables related to meeting the cdc/acsm physical activity guidelines. Medicine Science Sports Exercises., 32(12), 2087-92.

Ölçücü, B., Vatansever, Ş. Özcan, G., Çelik, A. Paktaş, Y. (2015). Üniversite öğrencilerinde fiziksel aktivite düzeyi ile depresyon ve anksiyete ilişkisi. Uluslararası Türk Eğitim Bilimleri Dergisi, 3(4), 294-303.

Öztürk, M. (2005). Üniversitede ĕgitim-öğretim gören öğrencilerde uluslararası fiziksel aktivite anketinin geçerliliği ve güvenirliği ve fiziksel aktivite düzeylerinin belirlenmesi. Yüksek Lisans Tezi. Hacettepe Üniversitesi Sağlık Bilimleri Enstitüsü.

Pols, M.A., Peeters, P.H., Kemper, H.C., et al.( 1998). Methodological aspects of physical activity assessment in epidemiological studies. Eur J Epidemiol., 14, 63- 70.

Savcı, F. D. S., Öztürk, U. F. M., Arıkan, F. D. H. (2006). Üniversite öğrencilerinin fiziksel aktivite düzeyleri. Türk Kardiyoloji Derneği Arşivi Dergisi, 34(3),166-172.

Saygın, M., Öngel, K., Çalışkan, S., Yalçın, M. A., Has, M., Gonca, T., Kurt, Y. (2011). Süleyman Demirel üniversitesi öğrencilerinin beslenme alışkanlıkları. S.D.Ü. Tıp Fak. Derg., 18(2), 43-47.

Scott, B., Martın, J.R. Morrow, Jr., Allen, W. Jackson, \& Andrea, L. Dunn. (2000). Variables related to meeting the CDC/ACSM physical activity guidelines. Official Journal of the American College of Sports Medicine Medicine and Science in Sports and Exercise, 32(12), 2087-2092.

Shi, Z., Lien, N., Kumar, B.N., et al. (2006). Physical activity and associated socio-demographic factors among school adolescents in Jiangsu Province, China. Prev Med., 43:218-221.

Soyuer, F.,Ünalan, D., Elmalı, F. (2010). Normal ağırlıklı ve obez üniversite öğrencilerinde fiziksel aktivite. Uluslararası Insan Bilimleri Dergisi, 7(2), 862-872.

Uluöz, E., Yılmaz, C. Y., Dinç, Z. F. (2017). Farklı fakültelerde görev yapan akademisyenlerin fiziksel aktiviteye katılım durumlarının incelenmesi. Uluslararası Kültürel ve Sosyal Araştırmalar Dergisi (UKSAD), 3 (Special Issue 2), 326-336.

Üçok K., Genç A., Şener Ü., Akkaya M., Mollaoğlu H., (2011). Investigation of physical activity level of medical school students. European Journal of Basic Medical Sciences, 1(1), 33-38.

Von Bothmer, M.I., Fridlund, B. (2005). Gender differences in health habits and in motivation for a healthy life style among Swedish university students. Nurs Health Sci.,7:107-18.

WHO -The World Health Report.(2002). Reducing Risks, Promoting Healthy Life. Erişim Linki: http://www.who.int/whr/2002/en/ Erişim Tarihi: 03.09.2019. 